Pharmaciana

Vol.7, No.1, Mei 2017, Hal. 71-78

ISSN: 2088 4559; e-ISSN: 24770256

\title{
Mutu sabun transparan ekstrak etanol herba pegagan (Centella asiatica L.) setelah penambahan sukrosa
}

\author{
Andarini Siwi Mumpuni ${ }^{1}$, Heru Sasongko ${ }^{* 1,2}$ \\ ${ }^{1}$ Prodi D3 Farmasi, Fakultas Matematika Dan Ilmu Pengetahuan Alam, \\ ${ }^{2}$ Prodi S1 Farmasi, Fakultas Matematika Dan Ilmu Pengetahuan Alam, \\ Universitas Sebelas Maret, Surakarta \\ Jl Ir Sutami No 36 A Kentingan Surakarta 57126
}

Submitted: 04-02-2017

Reviewed: 23-03-2017

Accepted: 05-05-2017

\begin{abstract}
ABSTRAK
Pegagan (Centella asiatica L.) adalah tanaman obat yang mengandung zat antioksidan yang dipercaya dapat mengatasi berbagai permasalahan kulit seperti keloid, selulit, dan noda hitam. Berbagai manfaat dan khasiat yang terdapat pada herba pegagan, mendorong untuk diaplikasikan pada berbagai bentuk sediaan farmasi untuk mendapatkan nilai tambah. Salah satu cara yang dapat dilakukan adalah membuat formulasi ekstrak herba pegagan pada sediaan sabun mandi transparan. Pada proses pembuatan sabun transparan, gula pasir berfungsi untuk membantu terbentuknya transparansi pada sabun. Tujuan dari penelitian ini untuk mengetahui pengaruh penambahan sukrosa terhadap peningkatan transparansi sabun, stabilitas sifat fisik sebelum dan sesudah penyimpanan selama 8 minggu. Sabun transparan ekstrak pegagan divariasi dengan konsentrasi sukrosa 11\%, 13\%, dan $15 \%$. Sabun yang dihasilkan dilakukan serangkaian pengujian sifat fisik dan kimia yang meliputi transparansi, pH, kadar air, dan kestabilan busa. Hasil penelitian menunjukkan bahwa penambahan sukrosa berpengaruh terhadap tingkat tranparansi Variasi konsentrasi sukrosa tidak mempengaruhi nilai $\mathrm{pH}$ dan stabilitas busa $(>0,05)$. Stabilitas sifat fisis dan kimia selama 8 minggu menunjukkan tidak ada perbedaan yang signifikan kecuali kadar air sabun nilai signifikasi berkisar 0,00-0,046 < 0,05 .
\end{abstract}

Kata kunci: pegagan, sabun transparan, sukrosa

\begin{abstract}
Centella asiatica L. is a kind of herbs which contains antioxidant that be trusted to overcome of various skin problems such as keloids, cellulite, and black stains. One of the additional ingredients used to make the transparent soap is sucrose or frequently called white sugar. In the process of making the transparent soap, white sugar is served to help the transparency of soap. The purpose of this research is to find out the effect of increasing the sucrose toward the degree of the transparency of the soap, stability of physical properties before and after storage for eight weeks and find out the skin response towards the soap by doing irritability test towards some respondents. Pegagan extract transparent soap is varied with the concentration of sucrose $11 \%, 13 \%$, and $15 \%$. The soap which is produced is conducted with a series of tests of physical characteristics include transparency, $\mathrm{pH}$, water content, and the stability of the foam.
\end{abstract}

\footnotetext{
Penulis korespondesi:

Heru Sasongko

Prodi D3 Farmasi, Fakultas Matematika Dan Ilmu Pengetahuan Alam

Universitas Sebelas Maret, Surakarta

J1 Ir Sutami No 36 A Kentingan Surakarta 57126

Email: heru_sasongko@staff.uns.ac.id
} 
The results showed that the addition of sucrose affect the increase in the level of transparency of the soap. Variations of sucrose concentration do not affect the $\mathrm{pH}$ value and stability of the foam $(>0.05)$. Physical properties and chemical stability for 8 weeks showed no significant difference except soapy water content ranged from $0.00-0.046$ significance value $<0.05$

Keywords: centella asiatica, transparent soap, sucrose

\section{PENDAHULUAN}

Industri sabun mandi dalam dekade ini saling berlomba untuk menciptakan produk sabun mandi yang inovatif dan berkualitas. Saat ini mulai banyak produsen sabun mandi yang melirik pada bahan alam untuk dijadikan bahan aktif pembuatan sabun mandi. Pegagan (Centella asiatica L.) adalah tumbuhan obat yang mengandung triterpenes, asiaticoside, madecasosside, asiatic acid dan madecassic acid yang dapat digunakan untuk mengatasi permasalahan kulit seperti keloid, selulit, dan noda hitam (Bylka et al., 2014). Ekstrak pegagan dalam industri obat tradisional telah teruji klinik untuk pengobatan luka, luka bakar, borok pada kulit, dan pencegahan keloid serta hipertrofi (Pramono dan Ajiastuti, 2005). Berbagai manfaat dan khasiat yang terdapat pada herba pegagan, mendorong untuk diaplikasikan pada berbagai bentuk sediaan farmasi untuk mendapatkan nilai tambah. Salah satu cara yang dapat dilakukan adalah membuat formulasi ekstrak herba pegagan pada sediaan sabun mandi transparan. Sabun mandi merupakan salah satu kebutuhan setiap orang untuk menjaga kebersihan tubuh. Formulasi ekstrak pegagan di dalam sabun akan mempermudah masyarakat untuk memanfaatkan khasiat yang ada.

Seiring makin beragamnya kebutuhan dan selera konsumen, produk sabun pun kini sangat bervariasi, seperti sabun opaque, sabun cair, dan sabun transparan, salah satu produk sabun yang makin diminati konsumen (Kailaku, 2011). Masing-masing jenis sabun tersebut memiliki keunggulan tersendiri, seperti aroma, bentuk, dan fungsi. Sabun transparan atau juga disebut sabun gliserin adalah jenis sabun mandi yang dapat menghasilkan busa lebih lembut di kulit, memberikan penampakan berkilau dan umumnya relatif lebih mahal jika dibandingkan dengan jenis sabun yang lain (Hambali dan Umiarti, 2004). Sabun transparan merupakan hasil reaksi penyabunan antara asam lemak dan basa kuat seperti sabun mandi biasa. Perbedaan di antara keduanya hanya terletak pada penampakan yang transparan dan tidak transparan (Mitsui, 1997). Pada proses pembuatan sabun transparan, gula pasir dapat berfungsi untuk membantu terbentuknya transparansi pada sabun dan membantu perkembangan kristal pada sabun (Priani dan Lukmayani, 2010). Berdasarkan hal tersebut, maka dilakukan penelitian tentang pengaruh variasi konsentrasi sukrosa sebagai transparent agent dalam formulasi sabun transparan untuk meningkatkan kualitas sabun dari ekstrak pegagan.

\section{METODE PENELITIAN}

Alat dan Bahan

Alat yang digunakan selama pembuatan produk antara lain; masker, sarung tangan, hot plate (Cimarec), wadah, gelas beaker (Pyrex), gelas ukur (Pyrex), pengaduk kaca, sendok tanduk, cetakan sabun, timbangan analit (Precisa Balances), termometer, $\mathrm{pH}$ meter (Inolab $\mathrm{pH}$ level 1 ivo seri 03450079), oven (Memmert), tabung reaksi (Pyrex), cawan porselin, cawan petri, kertas saring, corong kaca, dan alat pendukung lain. Bahan yang digunakan adalah asam stearat (teknis), $\mathrm{NaOH} 30 \%$ (teknis), gliserin (teknis), etanol (teknis), gula, dietanolamida (coco-DEA) (teknis), $\mathrm{NaCl}$ (teknis), aquadest, minyak kelapa (pasar Legi kota Surakarta) dengan kualitas food grade, minyak zaitun (teknis), dan herba pegagan (B2P2TO2T Tawang Mangu).

\section{Jalannya Penelitian \\ Preparasi sampel}

Ekstrak pegagan dibuat dibuat dengan cara maserasi, yaitu $250 \mathrm{~g}$ serbuk herba pegagan (simplisia kering yang sudah dihancurkan) dengan $1.250 \mathrm{ml}$ etanol $70 \%$ ditutup pada wadah kedap udara dan dibiarkan selama 24 jam dalam tabung kaca kedap udara dan terlindung dari cahaya, sambil 
berulang-ulang diaduk. Setelah 24 jam, ampas diperas menggunakan kain flanel. Maserat yang dihasilkan kemudian diuapkan hingga diperoleh ekstrak kental (Pramono dan Ajiastuti, 2005).

\section{Pembuatan sabun}

Pembuatan sabun transparan diawali dengan pencampuran antara fraksi lemak, yaitu asam stearat dan minyak nabati (campuran minyak kelapa dan minyak zaitun) pada suhu $70^{\circ} \mathrm{C}$, perlahan diturunkan hingga suhu menjadi $50^{\circ} \mathrm{C}$. Ditambahkan dengan fraksi alkali, yaitu $\mathrm{NaOH}$, untuk membentuk stok sabun. Stok sabun harus merupakan reaksi yang sempurna antara asam lemak dengan alkali, untuk menghindari adanya sisa asam lemak atau alkali bebas yang tertinggal dalam sabun.

Stok sabun yang terbentuk ditambahkan etanol hingga sebagian larut. Larutan sukrosa ditambahkan diikuti bahan-bahan lain, yaitu gliserin, $\mathrm{NaCl}$, dan coco-DEA. Masa adonan diaduk dengan kecepatan konstan pada suhu $70-80^{\circ} \mathrm{C}$, sampai semua bahan tercampur dengan sempurna dan terlihat transparan.

Suhu diturunkam menjadi $55^{\circ} \mathrm{C}$, kemudian ekstrak pegagan dimasukkan.Tahap berikutnya adalah pencetakan. Adonan sabun yang masih panas langsung dituangkan ke dalam cetakan. Setelah dingin, sabun akan mengeras dan dapat dikeluarkan dari cetakannya (Purnamawati, 2006).

Tabel I. Modifikasi formula sabun transparan ekstrak etanol herba pegagan (Centella asiatica L.) (Hambali et al., 2005)

\begin{tabular}{|c|c|c|c|c|}
\hline \multirow[t]{2}{*}{ Komposisi } & \multirow[t]{2}{*}{ Kegunaan } & \multicolumn{3}{|c|}{ Kandungan (gram) } \\
\hline & & $\begin{array}{c}\text { Formula } \\
\text { I } \\
\end{array}$ & Formula II & Formula III \\
\hline Asam Stearat & $\begin{array}{c}\text { Pengeras dan penstabil } \\
\text { busa }\end{array}$ & 56 & 56 & 56 \\
\hline $\mathrm{NaOH} 30 \%$ & Pereaksi Saponifikasi & 132 & 132 & 132 \\
\hline Gliserin & Humektan dan pelicin & 56 & 56 & 56 \\
\hline Etanol & Pelarut & 154,4 & 154,4 & 154,4 \\
\hline Gula & Transparent agent & 88 & 104 & 120 \\
\hline Dietanolamida (DEA) & $\begin{array}{c}\text { surfaktan atau penstabil } \\
\text { busa }\end{array}$ & 12 & 12 & 12 \\
\hline Minyak kelapa & Basis & 116 & 116 & 116 \\
\hline Minyak zaitun & Basis & 100 & 100 & 100 \\
\hline Air & Pelarut & 76 & 60 & 44 \\
\hline Ekstrak Pegagan & Bahan aktif & 8 & 8 & 8 \\
\hline $\mathrm{NaCl}$ & & 1,6 & 1,6 & 1,6 \\
\hline \multicolumn{2}{|c|}{ Berat total $(\mathrm{g})$} & 800 & 800 & 800 \\
\hline
\end{tabular}

Keterangan:

Formula I: sabun transparan dengan glukosa $11 \%$

Formula II: sabun transparan dengan glukosa $13 \%$

Formula III: sabun transparan dengan glukosa $15 \%$

\section{Pengujian sifat fisik}

Pengujian mutu produk dan stabilitas sediaan meliputi penentuan $\mathrm{pH}$, kadar air, tingkat transparansi, stabilitas busa. Pengamatan dilakukan setiap minggu selama 8 minggu, untuk mengetahui stabilitas sifat fisis fisiksabun tersebut. Cara keja sesuai dengan ketentuan Badan Standarisasi Nasional (BSN, 1994).

\section{Uji pH}

Pengukuran nilai $\mathrm{pH}$ dilakukan dengan menggunakan $\mathrm{pH}$ Meter pada larutan sampel 10\%, yang dibuat dengan melarutkan 1 gram sampel ke dalam $9 \mathrm{~mL}$ air. Pengukuran dilakukan pada suhu $25^{\circ} \mathrm{C}$ dengan cara mencelupkan elektroda $\mathrm{pH}$ Meter yang telah dibilas dengan air suling ke dalam larutan 
sampel. Nilai $\mathrm{pH}$ ditentukan setelah angka yang terbaca pada $\mathrm{pH}$ Meter menjadi stabil. Pengukuran dilakukan sebanyak 3 kali pengulangan.

\section{Kadar air}

Sampel sebanyak 5 gram ditempatkan di dalam wadah tahan panas, kemudian dipanaskan dalam oven bersuhu $105^{\circ} \mathrm{C}$ selama $2 \mathrm{jam}$. Sampel ditimbang setelah didinginkan. Pengukuran dilakukan sebanyak 3 kali pengulangan.

\section{Tingkat tranparansi}

Tingkat transparansi diamati secara visual,dengan menggunakan selembar kertas yang terdapat garis berwarna merah. Kemudian sabun diletakkan diatas dan diamati kejelasan warna garis merah tersebut yang menembus sabun.

\section{Uji stabilitas busa}

Sebanyak 1 gram sampel dilarutkan dalam $9 \mathrm{~mL}$ air, dimasukkan ke dalam tabung reaksi, kemudian dikocok selama 30 detik. Busa yang terbentuk diukur tingginya. Sampel didiamkan selama 1 jam, kemudian tinggi busanya diukur kembali. Jika sampel yang diukur jumlahnya lebih dari satu, harus digunakan tabung-tabung reaksi yang dimensinya sama. Pengukuran dilakukan sebanyak 3 kali pengulangan.

\section{Analisa data}

Data stabilitas sifat fisik sabun disajikan dalam bentuk gambar dan dianalisis menggunakan statistik Kolmogorov-Smirnov untuk melihat normalitas data. Analisa dilanjutkan dengan-ANOVA $(\alpha=0.05)$ dan uji t-LSD untuk melihat perbedaan setiap kelompok.

\section{HASIL DAN PEMBAHASAN}

Hasil uji sifat fisik dan stabilitas sabun transparan dari ekstrak etanol herba pegagan (Centella asiatica L.) disajikan pada Gambar 1 dan Gambar 2

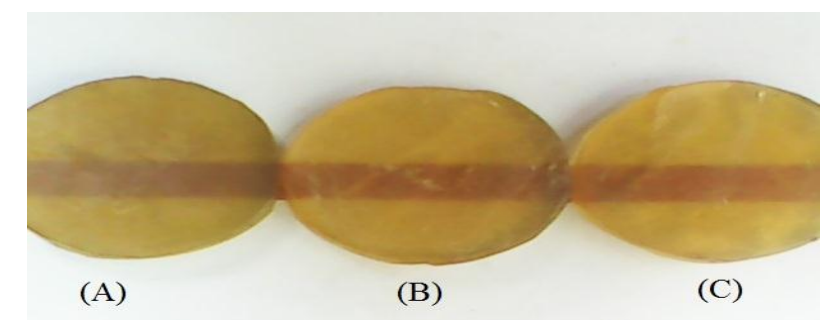

Gambar 1. Peringkat transparansi sabun berdasarkan konsentrasi sukrosa $11 \%$ (A) sukrosa 13\% (B) dan sukrosa $15 \%(C)$

\section{Uji transparansi sabun}

Pada Gambar 1 terlihat bahwa pada setiap formula memiliki dimensi gradasi transparansi warna sabun yang berbeda. Hal ini berarti peningkatan konsentrasi sukrosa atau gula pasir berbanding lurus dengan tingkat transparansi sabun. Selain berpengaruh terhadap tingkat transparansi, sukrosa juga dapat berfungsi sebagai humektan, sehingga dengan adanya sukrosa akan membuat sabun transparan tampak menarik, lembut dan juga dapat merawat kulit dengan baik (Mitsui, 1997). 


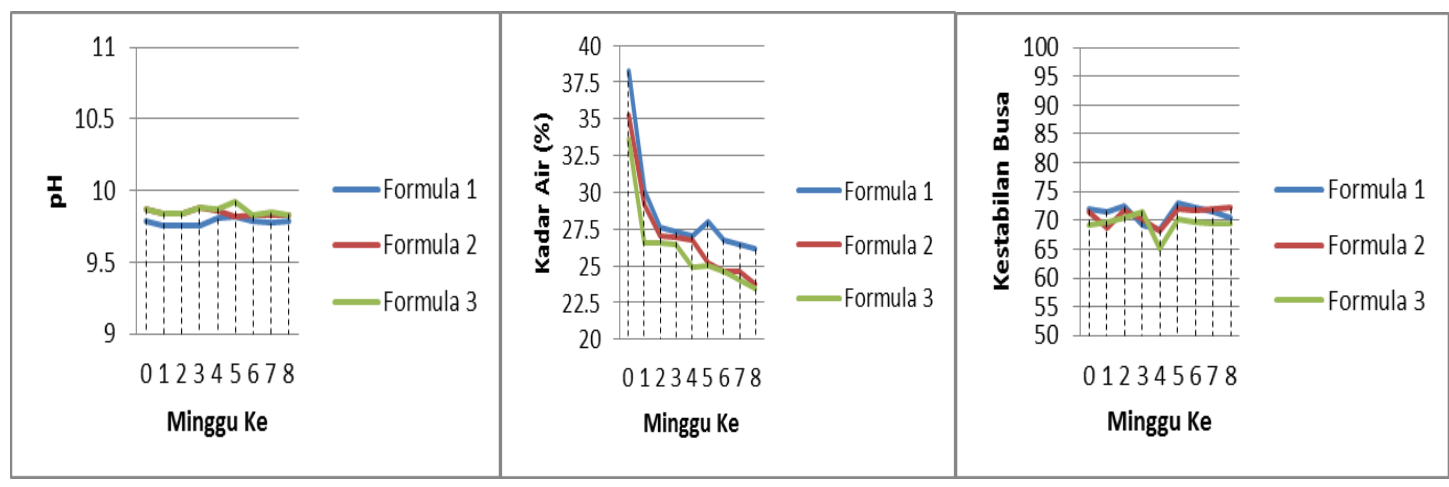

(A)

(B)

(C)

Gambar 2. Hasil pengujian hubungan antara variasi kadar sukrosa terhadap pH sabun selama 8 minggu (A); hubungan antara variasi kadar sukrosa terhadap kadar air sabun selama 8 minggu (B); hubungan antara variasi kadar sukrosa terhadap kestabilan busa selama 8 minggu (C)

\section{Uji pH}

Pada Gambar 2 dapat dilihat bahwa selama kurun waktu 8 minggu pH sabun masih berada pada rentang yang sama yaitu 9,7 -9,9. Ini dapat disimpulkan analisa menggunakan pendekatan secara teoritis stabilitas sabun baik formula 1, 2 maupun 3 masih baik. Standar nilai pH untuk sabun mandi berkisar antara 9-11 (Hernani et al., 2010). Tingkat alkali bebas dalam sabun ini disebabkan oleh adanya alkali yang tidak bereaksi dengan asam lemak dalam proses saponifikasi (Zulkifli dan Estiasih, 2014). Besarnya jumlah alkali dalam tiap formula adalah sama, sehingga $\mathrm{pH}$ antar formula tidak memiliki perbedaan yang cukup signifikan.Jumlah sukrosa yang diberikan tidak mempengaruhi $\mathrm{pH}$ sabun karena jumlah alkali yang ada dalam sabunlah yang mempengaruhi besarnya nilai $\mathrm{pH}$.

\section{Uji kadar air dan zat menguap lainnya}

Jumlah air dan zat menguap dalam sabun mempengaruhi karakteristik sabun yang disimpan. Sabun dengan kadar air dan zat menguap yang sangat tinggi lebih cepat mengalami penyusutan bobot. Selain itu, banyaknya air yang ditambahkan pada sabun akan berpengaruh terhadap kelarutan sabun. Semakin banyak air yang terkandung dalam sabun makan sabun akan mudah menyusut pada saat digunakan (Spitz, 2016). Menurut Saudi Arabian Standard Organization (SASO) 2008 kadar air dan bahan menguap yang baik adalah minimal 17\%. Berdasarkan ketentuan ini, sabun mandi yang dihasilkan selama 8 minggu pada Formula 1, 2 maupun 3 masih memenuhi persyaratan, karena kadar air dan bahan menguap lainnya memiliki nilai diatas $22 \%$. Dari Gambar 2 juga dapat dilihat bahwa pada minggu ke-1 dibandingkan minggu ke-0 terjadi penurunan kadar air sabun yang cukup signifikan. Ketidakstabilan ini dimungkinkan sabun mengalami proses pengeringan secara alami atau menjadi lebih kering karena pengaruh lingkungan.

Tabel II. Data hasil pengukuran kestabilan busa selama 8 minggu

\begin{tabular}{cccc}
\hline Minggu ke- & \multicolumn{3}{c}{ Rata -rata (\%) } \\
\cline { 2 - 4 } & Formula I & Formula II & Formula III \\
\hline 0 & $71,94 \pm 2,31$ & $71,35 \pm 4,33$ & $69,09 \pm 3,39$ \\
1 & $71,51 \pm 2,56$ & $68,75 \pm 2,64$ & $69,77 \pm 2,74$ \\
2 & $72,47 \pm 1,05$ & $71,78 \pm 2,22$ & $70,39 \pm 0,35$ \\
3 & $69,27 \pm 5,86$ & $70,23 \pm 2,47$ & $71,53 \pm 3,70$ \\
4 & $68,40 \pm 2,44$ & $68,19 \pm 1,17$ & $65,15 \pm 3,57$ \\
5 & $72,94 \pm 0,66$ & $71,88 \pm 0,99$ & $70,25 \pm 8,98$ \\
6 & $72,33 \pm 3,97$ & $71,77 \pm 1,39$ & $69,61 \pm 1,95$ \\
7 & $71,51 \pm 0,86$ & $72,09 \pm 0,38$ & $69,39 \pm 2,16$ \\
8 & $70,48 \pm 1,22$ & $72,12 \pm 3,03$ & $69,32 \pm 1,32$ \\
\hline
\end{tabular}




\section{Uji kestabilan busa}

Pada Tabel II terlihat persentase stabilitas busa dari setiap formula selama 8 minggu menunjukkan nilai yang hampir sama. Pengujian secara statistik menunjukkan tidak adanya perbedaan dari setiap formula dengan nilai signifikansi $>0,05$. Hal ini menunjukkan bahwa dengan adanya variasi konsentrasi sukrosa tidak mempengaruhi kestabilan busa. Hingga saat ini masih belum ada standar nilai yang pasti untuk kestabilan busa itu sendiri. Busa adalah dispersi gas-dalam-cairan yang distabilkan oleh suatu zat pembusa (surfaktan). Kecepatan pembentukan busa dan stabilitas busa merupakan dua hal penting untuk produk pembersih tubuh. Pada penggunaanya busa berperan dalam proses pembersihan dan melimpahkan wangi sabun pada kulit (Hernani et al., 2010). Pada umumnya konsumen beranggapan bahwa sabun yang baik adalah sabun yang menghasilkan banyak busa, padahal banyaknya busa tidak selalu sebanding dengan kemampuan daya bersih sabun. Karakteristik busa sendiri dipengaruhi oleh adanya bahan aktif sabun atau surfaktan atau penstabil busa (Martin et al., 1993). Busa yang banyak dan stabil lebih disukai daripada busa yang sedikit atau tidak stabil. Busa dapat stabil dengan adanya zat pembusa. Zat pembusa bekerja untuk menjaga agar busa tetap terbungkus dalam lapisan - lapisan tipis, dimana molekul gas terdispersi dalam cairan. Larutan yang mengandung bahan aktif akan menghasilkan busa yang stabil bila dicampur dengan air. Sukrosa tidak mengandung bahan - bahan aktif permukaan sehingga tidak memberikan pengaruh terhadap kestabilan busa (Purnamawati, 2006).

\section{KESIMPULAN}

Hasil penelitian menunjukkan bahwa konsentrasi sukrosa . Variasi konsentrasi sukrosa tidak mempengaruhi nilai $\mathrm{pH}$ dan stabilitas busa $(>0,05)$. Stabilitas sifat fisis dan kimia selama 8 minggu menunjukkan tidak ada perbedaan yang signifikan pada setiap formula dengan adanya variasi konsentrasi sukrosa, kecuali kadar air sabun nilai signifikasi berkisar 0,00-0,046 < 0,05. Kadar air yang turun bisa disebabkan oleh faktor suhu selama proses penyimpanan.

\section{UCAPAN TERIMAKASIH}

Ucapan terimakasih disampaikan kepada program studi D3 Farmasi FMIPA UNS atas kontribusinya dalam memfasilitasi alat dan bahan selama proses penelitian.

\section{DAFTAR PUSTAKA}

BSN, 1994, Standar Mutu Sabun Mandi., Dewan Standarisasi Nasional, Jakarta.

Bylka, W., Znajdek-Awiżeń, P., Studzińska-Sroka, E., Dańczak-Pazdrowska, A., Brzezińska, M., 2014, Centella asiatica in dermatology: An overview, Phytother. Res, 28: 1117-1124.

Hambali, E., Bunasor, T.K., Kusumah, A.S. dan G.A., 2005, Aplikasi dietanolamida dari asam laurat minyak inti sawit pada pembuatan sabun transparan, J. Teknol. Ind. Pertan., 15.

Hambali, E., Suryani, A. dan Umiarti, E.I., 2004, Kajian pengaruh penambahan lidah buaya (Aloe vera) terhadap mutu sabun transparan, J. Teknol. Ind. Pertan., 14.

Hernani, H., Bunasor, T.K., Fitriati, F., 2010. Formula sabun transparan antijamur dengan bahan aktif ekstrak lengkuas (Alpinia galanga L.Swartz.), Bul. Penelit. Tanam. Rempah dan Obat 21.

Kailaku, S.I., 2011, Sabun Transparan Skala Rumah Tangga, Pusat Perpustakaan dan Penyebaran Teknologi Pertanian, Teknol. Pengolah., http://pustaka.litbang.pertanian.go.id/publikasisummary.php?contentID=wr335117, diakses pada tanggal 2 Februari 2017.

Martin, A.. J., Swarbrick, Cammarata, A., 1993, Buku Farmasi Fisik Edisi Ke-tiga, Jilid 2, UI Press, Jakarta.

Mitsui, T. 1997. New Cosmetic Science. Edisi Kesatu. Amsterdam: Elsevier Science B.V. Hal. 13,1921.

Pramono, S., dan Ajiastuti, D., 2005, Standardization of pegagan extract (Centella asiatica (L.) Urban) based on siaticoside content using TLC densitometric method, Indones. J. Pharm. 118-123.

Priani, S.E., dan Lukmayani, Y., 2010, Pembuatan sabun transparan berbahan dasar minyak jelantah serta hasil uji iritasinya pada kelinci, Pros. SNaPP Sains dan Teknol., 1: 36-53. 
Purnamawati, D., 2006, Kajian Pengaruh Konsentrasi Sukrosa dan Asam Sitrat terhadap Mutu Sabun Transparan, Skripsi, Instutut Pertanian Bogor.

Spitz, L., 2016, Soap Manufacturing Technology, AOCS Press, London, Hal.133

Zulkifli, M., dan Estiasih, T., 2014, Sabun dari Distilat Asam Lemak Minyak Sawit: Kajian Pustaka, J. Pangan Dan Agroindustri, 2: 170-177. 
